\section{Comparación de datos regionales de efectividad de tratamiento de HTA según la ENS e informes REM}

Comparison of regional data of effectiveness of treatment of hypertension according to the National Health Survey (Chile) and the Monthly Statistical Reports

\section{Sr Editor:}

El tratamiento y control de Enfermedades Crónicas (EC) a nivel de la Atención Primaria de Salud (APS) es clave para alcanzar un mayor bienestar en la población del mundo entero ${ }^{1,2}$. Por esto la APS es un tema políticamente relevante y ya se plantea como tópico para las próximas elecciones presidenciales.

Sin embargo, no es fácil evaluar su rendimiento. Una herramienta utilizada en el sistema público chileno son los Resúmenes Estadísticos Mensuales $(\mathrm{REM})^{3}$. Las entidades administradoras de la Salud Municipal (Corporaciones municipales y Departamentos de Salud municipal) son los responsables de construir y entregar estos informes, recibiendo estímulos o recortes financieros asociados al cumplimiento de algunas metas (IAAPS y Metas Sanitarias), que son construidas con información proveniente de los REM.

La Encuesta Nacional de Salud (ENS) ${ }^{4}$, realizada por expertos externos al sistema, entrega una instantánea de la situación nacional y regional (no es posible usarla para analizar la realidad comunal) cada seis años. Sin embargo, su frecuencia y diseño muestral dificultan el uso de su información para la gestión sanitaria de cada comuna.

Buscando relacionar la calidad de la gestión municipal del sistema de APS chileno, con el impacto en EC, comparamos los datos de efectividad del tratamiento de hipertensión arterial (HTA) de la población con nivel educacional menor a 12 años representada en la ENS 2010, con la población representada en los REM (construidos a partir de la agregación de los informes comunales de los datos de diciembre del año 2010, excluyendo la XI región, por la falta de disponibilidad de su información), para cada región del país.

Se debe considerar que los REM representan la realidad regional de todos los Centros de APS del país, mientras que la ENS utiliza una muestra representativa a nivel regional. Sin embargo, se decidió comparar ambas fuentes de información (ENS y REM), como un acercamiento hacia la validación de los datos provenientes de los REM.

Existen diferencias mayores en la efectividad del tratamiento de HTA calculada por la ENS y los REM, con un sesgo favorable a estos últimos. Mientras la variación de las mediciones de HTA en la ENS va desde $28 \%$ a $75 \%$, los REM muestran valores de 54\% a 77\% (ambos rangos aproximados). La desviación estándar en los datos de la ENS es de $12 \%$, mientras que en los REM es de sólo 5,87\%. (Figura 1 ).

Los datos están distantes y por encima de la realidad medida por la ENS (correlación de 0,024). Probablemente, esta diferencia está más relacionada con el cumplimiento de las metas exigidas, que con la realidad de la efectividad del tratamiento de la HTA (la efectividad nacional del tratamiento es de $63,5 \%$ considerando los REM, muy similar a $60 \%$ definido en las Metas Sanitarias ${ }^{5}$; en cambio de acuerdo a la ENS esta efectividad es de 52,1\%).

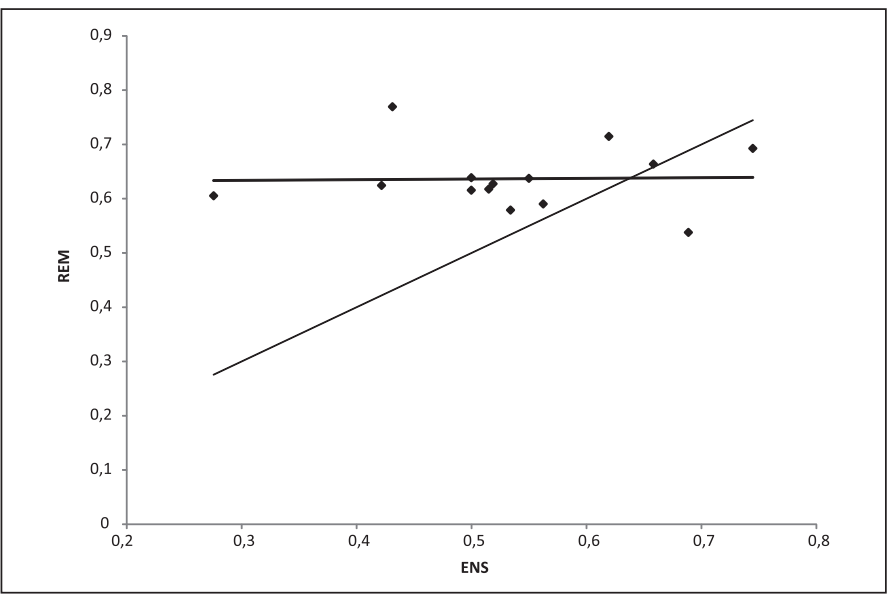

Figura 1. Comparación de datos de la efectividad del tratamiento de HTA para la ENS versus los REM. 
La conclusión que obtenemos de este breve análisis, es que la información entregada por los REM no es confiable si se la compara con los datos de la ENS. Esto es extraordinariamente relevante, porque sin información válida no puede haber gestión, y sin gestión es muy difícil realizar mejoras significativas en la APS ${ }^{6}$.

Para potenciar la APS es necesario conocer periódicamente la realidad local y los logros de los distintos prestadores, para lo cual se debe avanzar en la obtención de información relevante y confiable a ese nivel. Esta información permitiría tomar decisiones más oportunas y poder hacer una mejor gestión local. En este sentido cabe plantearse algunas preguntas claves: ¿Debiera la ENS ampliarse para hacerla representativa a nivel comunal? ¿Debieran validarse los REM por agencias externas? ¿Se debe acelerar el desarrollo de los sistemas de información para mejorar la confiabilidad de la información reportada? ¿Debiera modificarse la forma de acceder a la información para construir los IAAPS y las Metas Sanitarias?

Cristián Mansilla A. ${ }^{1}$, Joaquín Montero L. ${ }^{2}$, Nicolás Majluf S. ${ }^{3}$, María Paulina Rojas $V^{2}$ ${ }^{1}$ Gerencia de Análisis de Negocios. Red Salud UC.

${ }^{2}$ Departamento de Medicina, Facultad de Medicina.

${ }^{3}$ Escuela de Ingeniería Industrial y de Sistemas. Facultad de Ingeniería. Pontificia Universidad Católica de Chile. Santiago de Chile.

\section{Referencias}

1. Starfield B. Primary care: an increasingly important contributor to effectiveness, equity and efficiency of health services. Gac Sanit 2012; 26: 20-6.

2. Organización Mundial de la Salud. Informe sobre la Salud en el Mundo-La atención primaria de salud-Más necesaria que nunca. Ginebra: Ediciones de la OMS. 2008.

3. Ministerio de Salud. Departamento de Estadísticas e Información de Salud. 2011, www.deis.cl.

4. Ministerio de Salud. Encuesta Nacional de Salud ENS 2009-2010. Pontificia Universidad Católica de Chile, Facultad de Medicina, Santiago, Chile. 2010.

5. Ministerio de Salud. Metas Sanitarias y Mejoramiento de la Atención Primaria de Salud para el año 2010. Departamento de Asesoría Jurídica, Santiago, Chile. 2010.

6. Montero J, Majluf N, Corbalán J, Herrera C, Mansilla $\mathrm{C}$, Peñaloza B, et al. Elementos Claves para la Implementación de un Modelo de Gestión en la Salud Municipa. En Pontificia Universidad Católica de Chile editores. Santiago, Chile; Propuestas para Chile: Concurso Políticas Públicas 2011; 2011. p. 207-30.

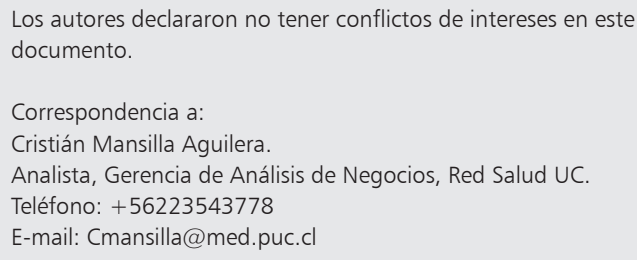

